\title{
Application of Ketone-Based Resins as Anticorrosive Coating
}

\author{
Esma Sezer, Nilgün Kizılcan, and Kerim Çoban \\ Chemistry Department, Faculty of Science and Letters, Istanbul Technical University, Istanbul 34469 Maslak, Turkey \\ Correspondence should be addressed to Esma Sezer, esezer@itu.edu.tr
}

Received 1 July 2010; Revised 15 October 2010; Accepted 5 November 2010

Academic Editor: Shengshui Hu

Copyright $\odot 2011$ Esma Sezer et al. This is an open access article distributed under the Creative Commons Attribution License, which permits unrestricted use, distribution, and reproduction in any medium, provided the original work is properly cited.

\begin{abstract}
Effect of some newly synthesized modified ketonic resins on corrosion inhibition of stainless steel (SS) and copper (Cu) was investigated in acidic medium. Carboxyl, hydroxyl, and carbonyl functionalized resins have been coated on metal electrode as a thin film by dipping method. Corrosion characteristics of coating on SS (304 L) and Cu were investigated by polarization, opencircuit, and impedance measurement. These measurements performed at different time and the stability of polymeric coating were tested with time in acidic medium. The resin coating was able to protect both the SS and copper.
\end{abstract}

\section{Introduction}

The corrosion of metals is an enormous economic problem. Thus, efforts to develop more efficient and environmentally compliant methods to prevent corrosion have been ongoing throughout this century [1]. Often, the best strategy to control corrosion of an active metal is to apply a protective surface coating. Polymers occupy a very specific place amongst anticorrosion techniques. Polymers combine good chemical resistance with impermeability to different media and unusual deformation characteristics $[2,3]$. Thermoplastic polymers include several applications in coated systems, as powder coatings [4], anticorrosive paints in automotive industry, and clean room applications [5]. Polyolefins have been widely used for this purpose. In the field of alkyd resins, solvent-borne paints are the most used in the market [6]. Polymer coatings provide corrosion protection by acting as a barrier layer between the substrate material and the environment [7-9]. It is well known that surface characteristics are an important factor determining the corrosion stability of the organic coatings [10-13]. This factor also affects the deposition behavior of the coatings. Although there are plenty of resins on the market, modern coating technology is focused to the need of development of high-performance polymeric materials [14-19]

Realization of the barrier and inhibition and electrochemical mechanisms of anticorrosion protection with the help of polymers not only allow a profound improvement in the anticorrosion protection of metal parts, but also come close to the creation of "smart" anticorrosion plastics and anticorrosion systems.

There are different techniques for corrosion measurements one of which is electrochemical one. After the publication of Menges and Schneider [20], applications of electrochemical impedance spectroscopy (EIS) become a powerful nondestructive tool for the evaluation of coating properties and their changes with exposure time $[3,21-30]$.

Resins with functional groups were synthesized in our previous study [31-33]. The aim of this work was to investigate corrosion performances of these carboxyl, hydroxyl, and carbonyl functional group containing ketonic resin coatings on SS and copper. The corrosion behavior of bare and resincoated $\mathrm{SS}$ and copper in $1 \mathrm{~N} \mathrm{H}_{2} \mathrm{SO}_{4}$ solutions was determined by EIS technique and polarization curves. Although the use of Tafel extrapolation is not recommended for polymercoated electrode due to ohmic drop through the film, these measurements were performed for qualitative information and $i_{\text {cor }}$ and $E_{\text {corr }}$ changes for different polymeric coatings were compared each other and bare electrode.

\section{Experimental}

2.1. Materials. Sulphuric acid, nitric acid, dichloromethane (DCM), acetone, ethyl alcohol are all analytical grade and used without further purification. Resins used are given 


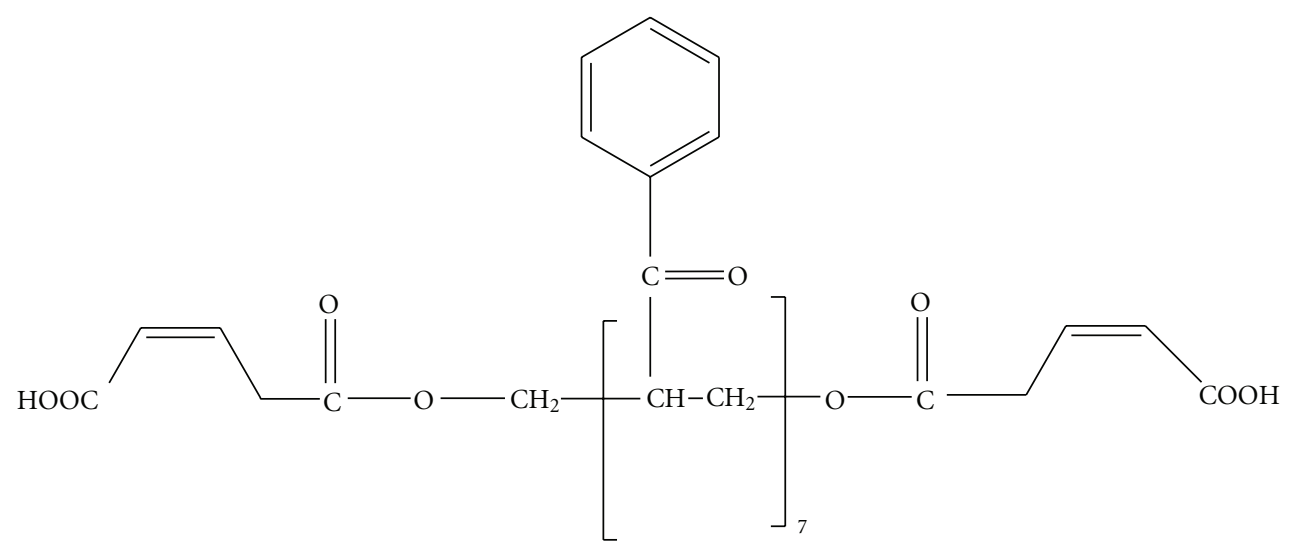

MA-AFR (maleic anhydride modified acetophenone formaldehyde resin)<smiles>CC(COC(=O)c1cccc(-c2ccc(C(=O)O)c(C(=O)O)c2)c1)C(C)C(=O)c1ccccc1</smiles>

BPDA-AFR (biphenyl-tetra carboxylic dianhydride modified acetophenone formaldehyde resin)<smiles>CCCCC(CC(=O)O)C(=O)OCC(C)C(CC(C)CCC(=O)O)C(=O)c1ccccc1</smiles>

DDSA-AFR (dodesenyl sucsinic anhydride modified acetophenone-formaldehyde resin)

Scheme 1: The molecular structure of the first group resins (MA-AFR, BPDA-AFR, DDSA-AFR).

names and abbreviations in Schemes 1,2, and 3 and they were synthesized as described previously [31-33].

2.2. Measurements. Electrochemical measurements were performed in three-electrode system by using Parstat 2263 model potentiostat. $\mathrm{Ag} / \mathrm{AgCl}$, Pt wire, copper, and stainless steel were used as reference electrode counter electrode, and working electrodes, respectively. All potentials were given versus $\mathrm{Ag} / \mathrm{AgCl}$ reference electrode. Metals were immersed into resin solutions, which are dissolved in dichloromethane, and thin films with different thicknesses $(5,15,35 \mu \mathrm{m})$ were obtained. The thicknesses of the coatings were measured by micrometer. Anodic and cathodic polarization curves of these films were experienced in $1 \mathrm{~N} \mathrm{H}_{2} \mathrm{SO}_{4}$ medium, and corrosion currents were calculated from Tafel extrapolation. All impedance spectra were measured at open circuit potential in the same medium frequency range between $10^{5}$ and $5 \cdot 10^{-3} \mathrm{~Hz}$ with an applied ac signal of $10 \mathrm{mV}$.

\section{Results and Discussion}

Anodic and cathodic polarization curves of coated and bare stainless steel and copper are obtained and given in Figure 1. 
<smiles>C=C(CC1(CO)CCCC(C(C)(C)CO)C1=O)c1cc(O)cc(C2(c3cccc(O)c3CCO)CCCCC2)c1</smiles>

$\mathrm{CB}_{6} \mathrm{FR}$ (cyclohexanone-bisphenol-C-formaldehyde resin)

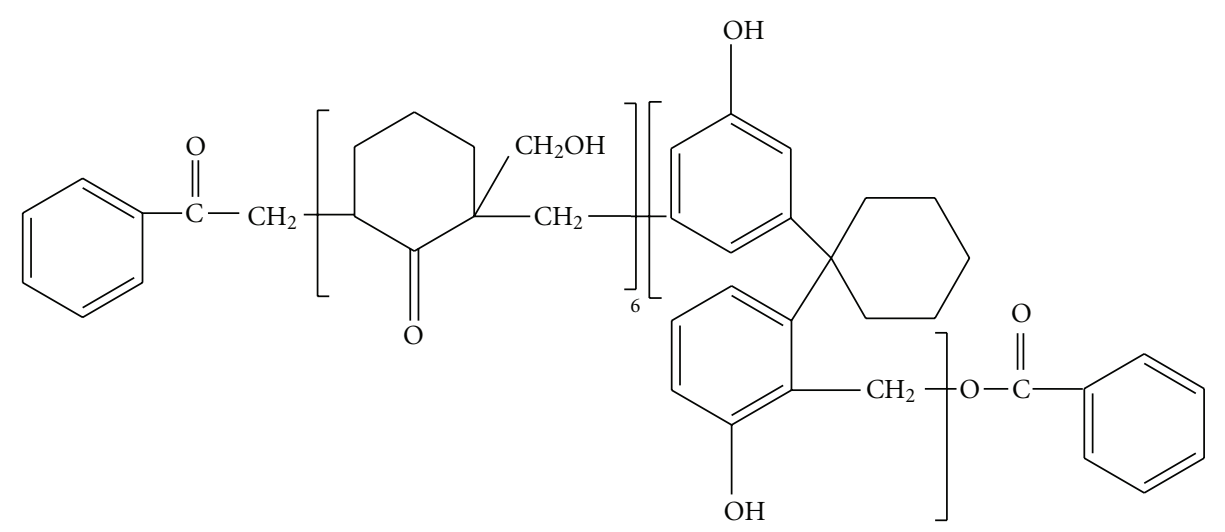

BenzCB $_{6} \mathrm{FR}$ (benzoylated cyclohexanone-bisphenol-C-formaldehyde resin)<smiles>C=C(CC1(CO)CCCC(C)(CC(C)=O)C1=O)CC1(c2cc(O)cc(C(C)=O)c2)CCCCC1</smiles>

As- $\mathrm{CB}_{6} \mathrm{FR}$ (acetylated cyclohexanone-bisphenol-C-formaldehyde resin)

Scheme 2: The molecular structure of the second group resins $\left(\mathrm{CB}_{6} \mathrm{FR}, \mathrm{BenzCB}{ }_{6} \mathrm{FR}, \mathrm{As}-\mathrm{CB}_{\mathrm{Ac}} \mathrm{FR}\right)$.

When the corrosion potentials of coated electrode were compared with bare SS, it could be concluded that corrosion potentials are mainly changed in anodic direction with resin coatings. This result showed that resin coatings prevent 


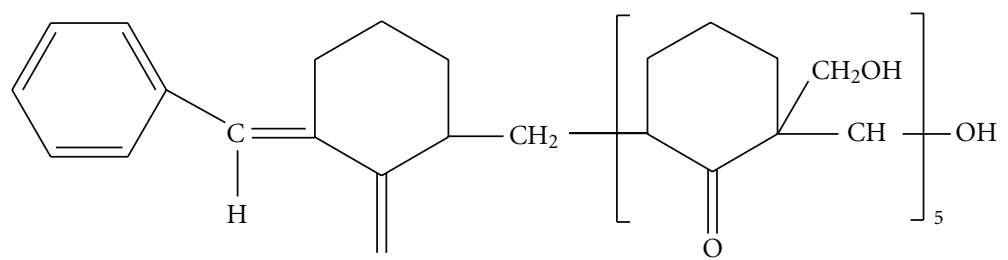

$\mathrm{CB}_{\mathrm{ZA}}$-FR (cyclohexanone-benzaldehyde-formaldehyde resin)<smiles>CC(C)(O)CC1CCCC(C(C)(CC2CCCC(CO)C2=O)C(=O)O)C1=O</smiles>

$\mathrm{CC}_{\mathrm{A}} \mathrm{FR}$ (cyclohexanone-citricacide-formaldehyde resin)

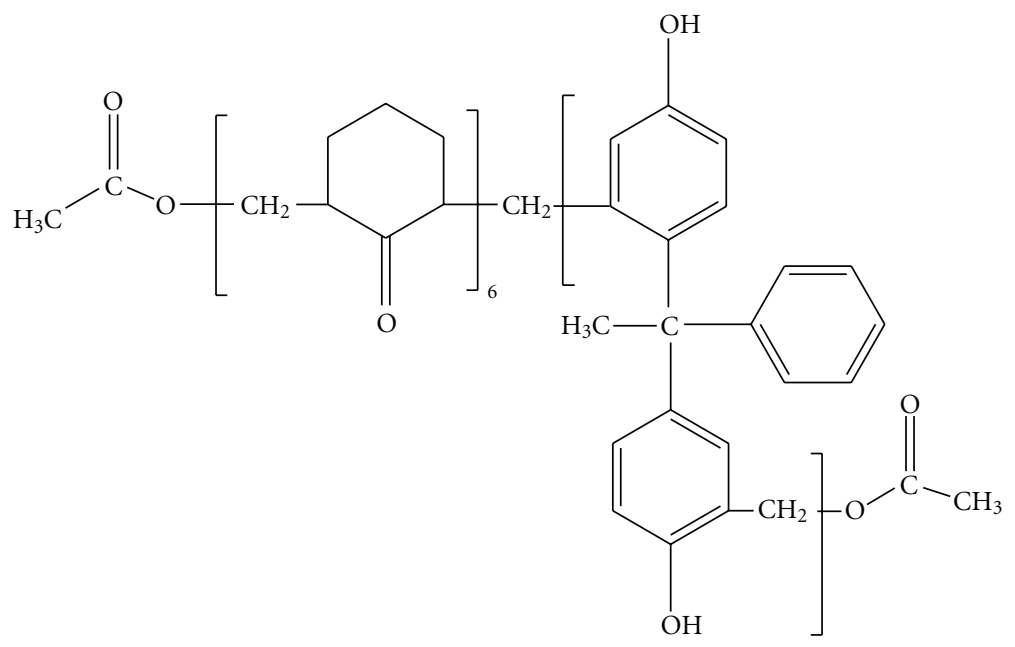

As- $\mathrm{CB}_{\mathrm{As}} \mathrm{FR}$ (Acetylated cyclohexanone -bisphenol AC-formaldehyde resin)

Scheme 3: The molecular structure of the third group resins $\left(\mathrm{CB}_{\mathrm{ZA}}-\mathrm{FR}, \mathrm{CC}_{\mathrm{A}} \mathrm{F}, \mathrm{As}_{-}-\mathrm{CB}_{\mathrm{Ac}} \mathrm{FR}\right)$.

anodic reaction by acting as a barrier layer between electrode surface and corrosion environment.

There is an only small shift in corrosion potentials of $\mathrm{CB}_{\mathrm{ZA}}-\mathrm{F}, \mathrm{BPDA}-\mathrm{AF}$ (From $-470 \mathrm{mV}$ to -468 and $-465 \mathrm{mV}$ resp.).). This result indicates that resins inhibit both anodic and cathodic reactions. $\mathrm{CB}_{6} \mathrm{~F}$ is the only resin that results in a shift in cathodic direction suggesting protection of cathodic reaction. Current densities of coated electrodes compared to the bare one decreased as expected.

Corrosion potentials of resin-coated copper changed generally in negative direction as compared to bare copper (Figure 1). Although corrosion rate decreased and high inhibition was obtained, corrosion potential has almost not changed with $\mathrm{MA}-\mathrm{AF}, \mathrm{CC}_{\mathrm{A}} \mathrm{F}$, and $\mathrm{AsCB}_{\mathrm{As}} \mathrm{F}$ resins. These results indicate both anodic and cathodic inhibition.

Although the use of Tafel analysis is not suggested for polymer coated electrode, it is performed to follow $E_{\text {cor }}$ and $i_{\text {corr }}$ changes qualitatively and to gain information on coating by comparing to bare electrode.

The open circuit potentials (OCPs) of bare and resincoated samples were monitored in $1 \mathrm{~N} \mathrm{H}_{2} \mathrm{SO}_{4}$ solution for 3 hours. The variation of OCP versus time for bare electrodes, coated SS, and copper electrodes were shown in Figures 2(a) and 2 (b) respectively. 


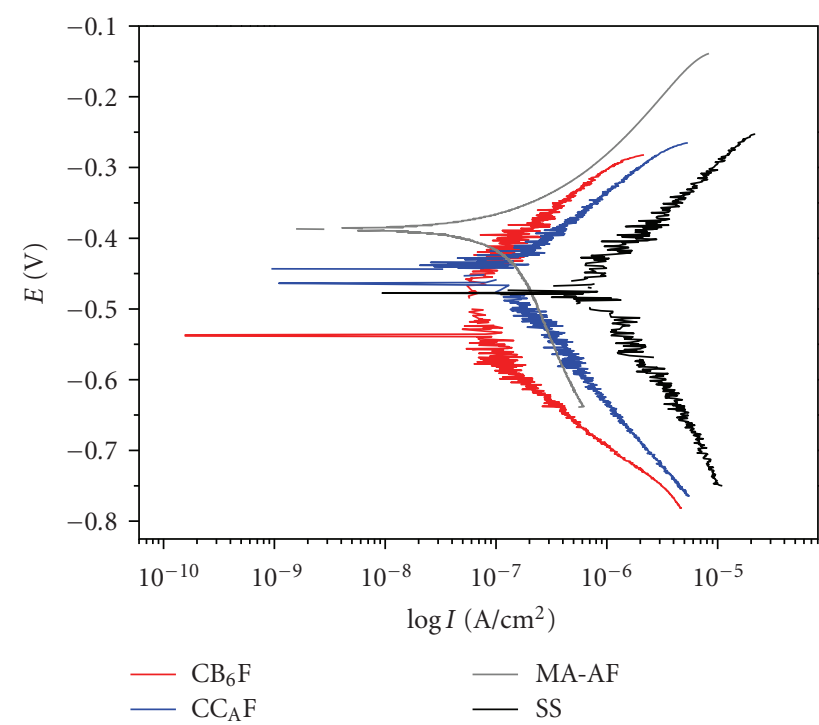

(a)

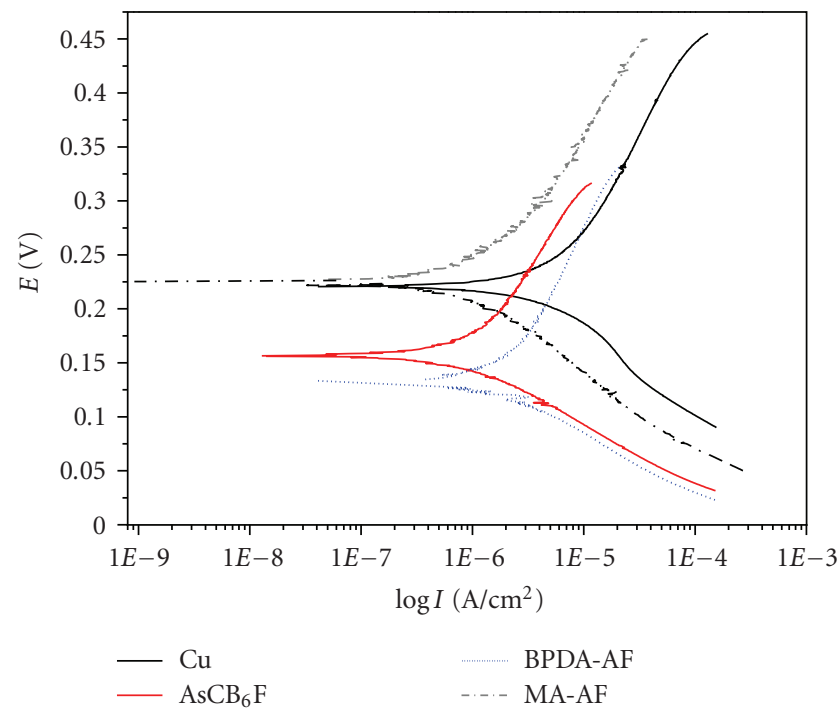

(b)

FIGURE 1: Polarization curves of bare and resins coated SS (a) in copper; (b) in $1 \mathrm{~N} \mathrm{H}_{2} \mathrm{SO}_{4}$.

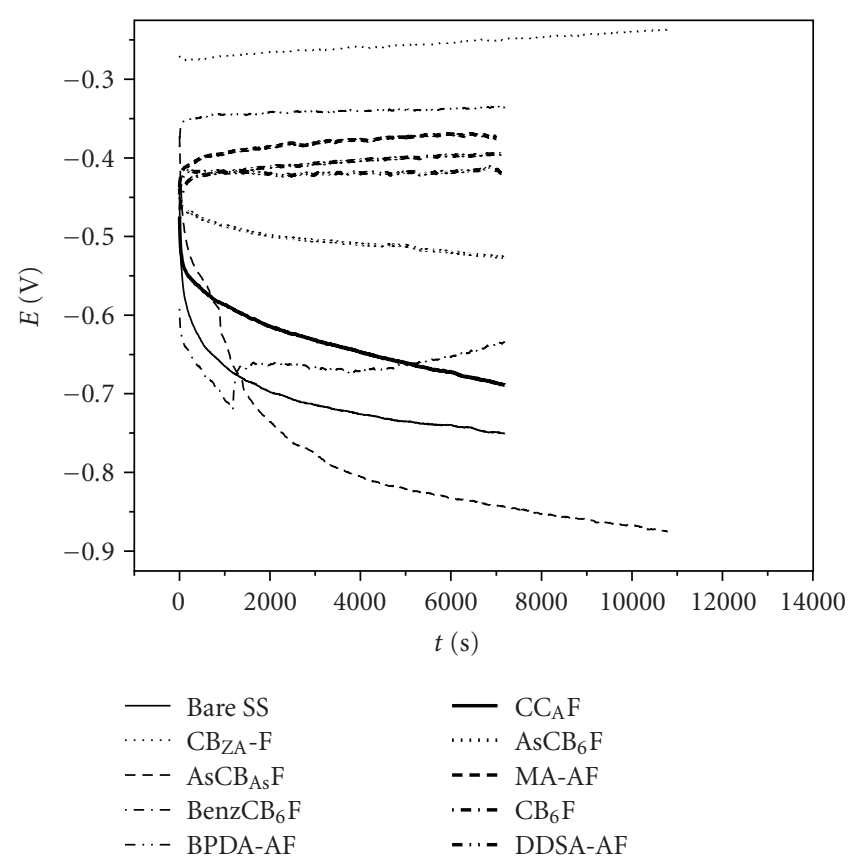

(a)

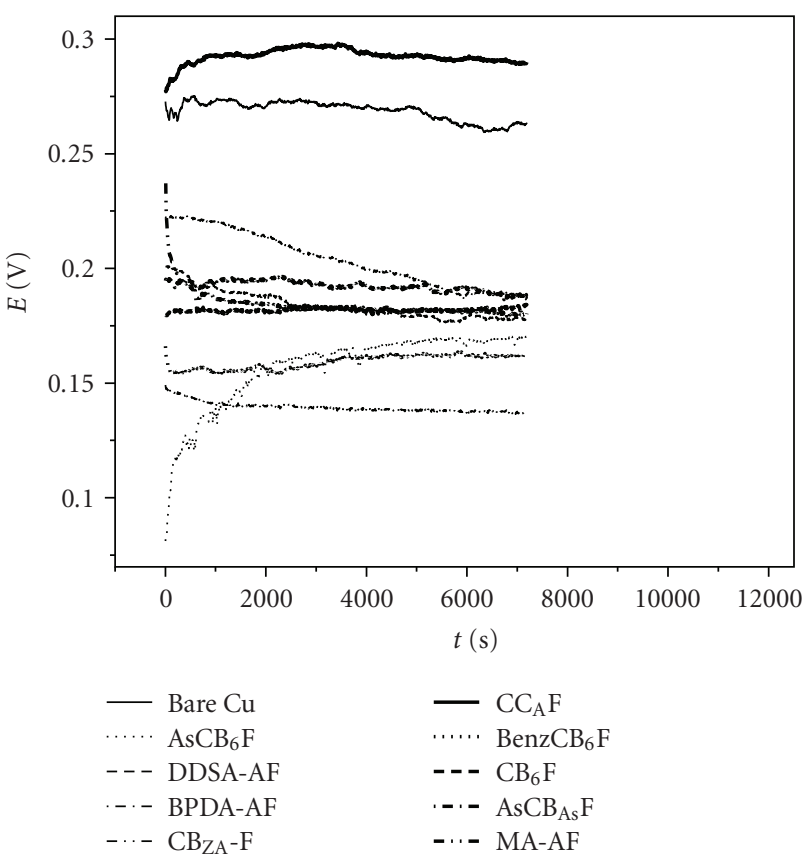

(b)

FIgURE 2: Variation of the open circuit potential versus time of bare and resin coated SS (a) in copper; (b) in $1 \mathrm{~N} \mathrm{H}_{2} \mathrm{SO}_{4}$.

The OCP values of coated steel are decreased initially, and the value for coated electrode shifted to noble direction compared to bare electrode. The result suggests that coating is able to passivate the SS surface. OCPs of bare and coated electrode stay almost constant after 33 minutes indicating stable behavior.

OCP of bare copper is higher than resin-coated electrode indicating a retardation of cathodic reaction that is the $\mathrm{H}_{2}$ evolution in our case. Stainless steel is more active than copper. Coating mainly inhibited the anodic reaction, and anodic potential shift was observed for SS. However, for copper coating seems to inhibit mainly the cathodic reaction.

EIS has established a very useful method for evaluating the polymer-coated metal system [3]. Inhibition of the corrosion of the substrate metal can be detected by measuring double layer capacitance $\left(C_{\mathrm{dl}}\right)$ and polarization resistance $\left(R_{\mathrm{p}}\right)$. The parameters obtained from these measurements are listed in Tables 1 and 2. 


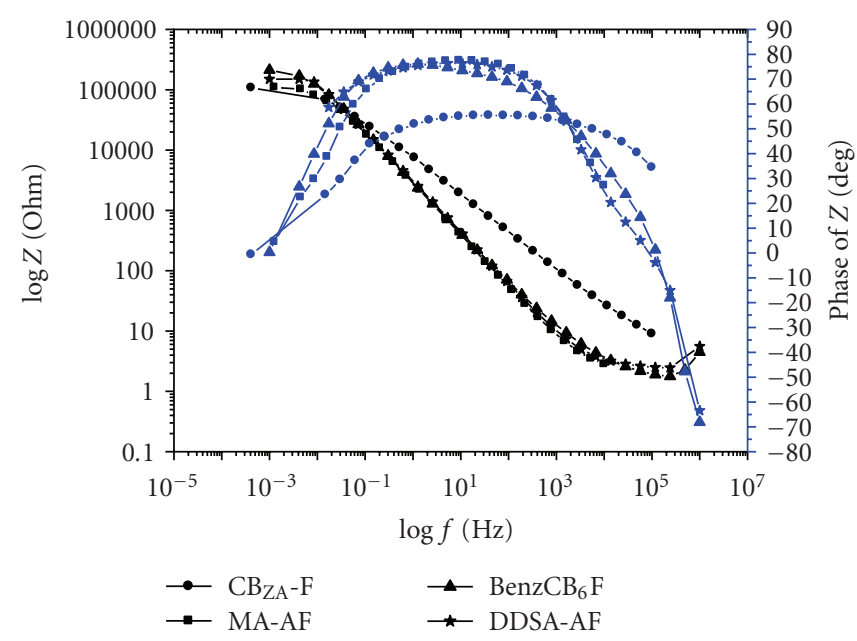

(a)

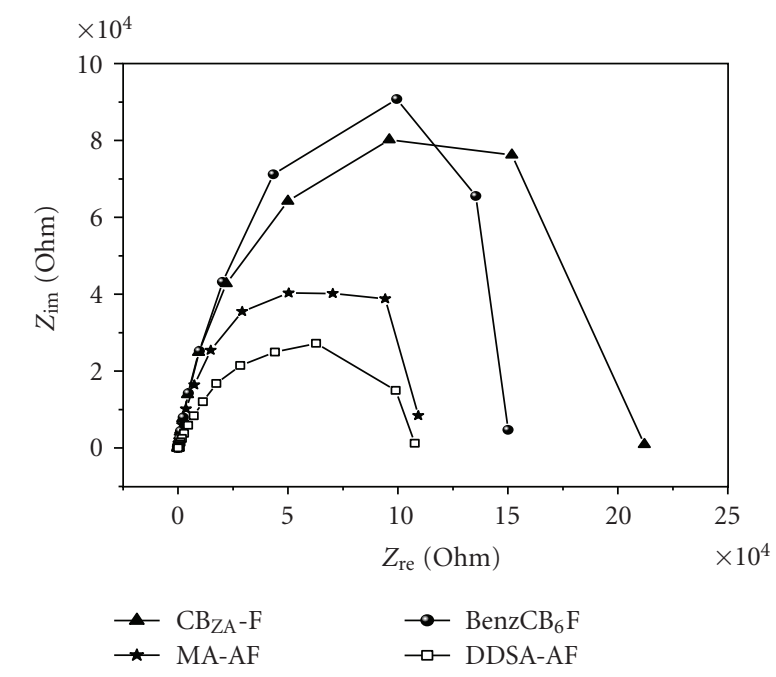

(b)

FIGURE 3: Bode (a) and Nyquist (b) diagram for resin coated SS.

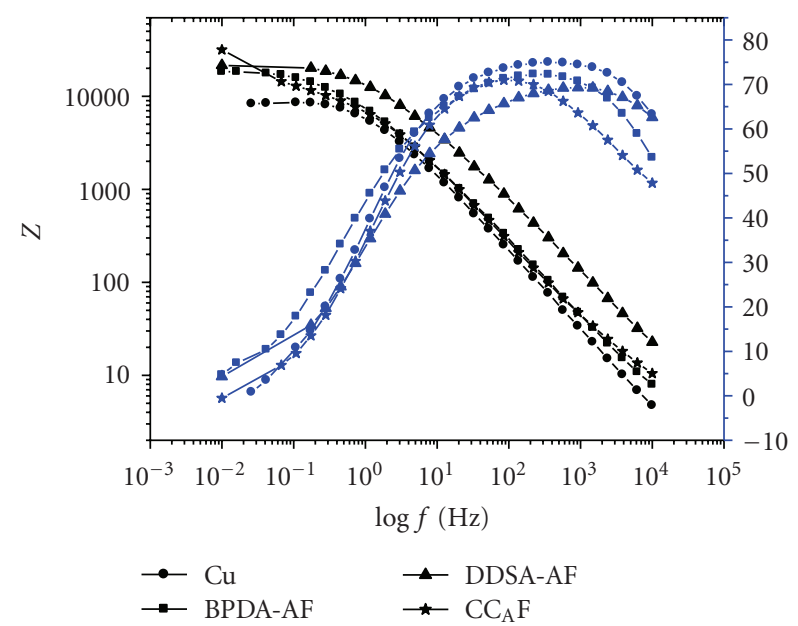

(a)

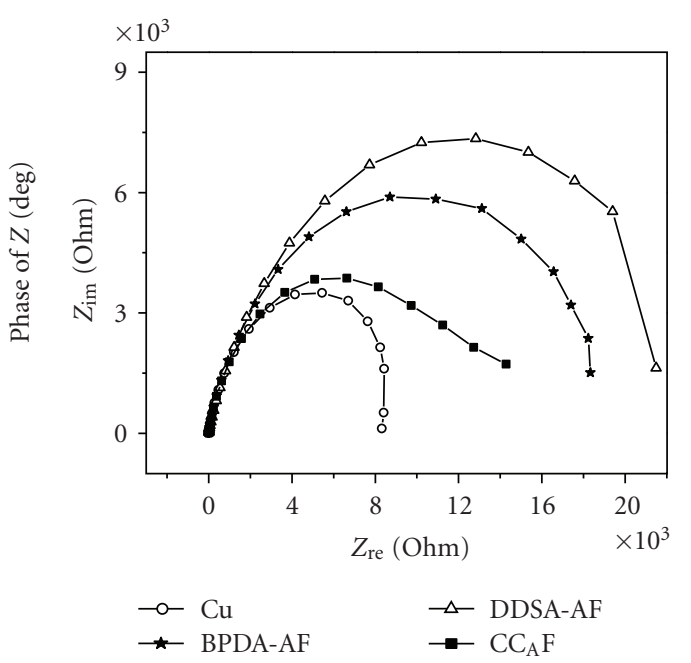

(b)

Figure 4: Bode (a) and Nyquist (b) diagrams for bare and resin coated copper.

Figures 3(a) and 3(b) depict the typical Bode and Nyquist impedance plots obtaining for the bare and resin-coated SS electrodes at an open circuit potential after 60 minutes immersion in $1 \mathrm{~N} \mathrm{H}_{2} \mathrm{SO}_{4}$.

High-frequency intercept of semicircle on the real axis yields the solution resistance $\left(R_{\mathrm{s}}\right)$ and low-frequency region yield the sum of $R_{\mathrm{s}}$ and $R_{\mathrm{p}}$. All these calculated values for SS electrodes were summarized in Table 1 for bare and coated SS. Polarization resistances of resin-coated SS electrodes increased according to impedance results. These results showed that protective film was obtained on the metal surface. Coatings are expected to overcharge surface reducing the pore density leading to the reduction in capacitive effect.
The semicircles are generally associated with the relaxation of the capacitors of electrical double layers with their diameters representing the charge transfer resistance. $\mathrm{CB}_{\mathrm{ZA}}$ $\mathrm{F}$ seems the largest curve with biggest diameter which means the highest polarization resistance. (Figure $3(\mathrm{~b})) . R_{\mathrm{p}}$ can be attributed to the electric resistance of ionic transfer through coating pores. As the film thickness increases, $R_{\mathrm{p}}$ values increase due to increase in electric resistance as expected (Table 1).

Impedance measurements results for copper electrode also showed that after coating, protecting film was formed and polarization resistance increased (Figure 4, Table 2).

When the coatings were compared with conventional paint, it can be easily seen that they are effective as much 
TABLE 1: Impedance parameters of bare and resin-coated SS in $1 \mathrm{~N} \mathrm{H}_{2} \mathrm{SO}_{4}$.

\begin{tabular}{|c|c|c|c|c|}
\hline \multirow{2}{*}{ Electrode } & \multirow{2}{*}{$C_{\mathrm{dl}} / \mathrm{A}\left(\mathrm{F} / \mathrm{cm}^{2}\right)$} & \multirow{2}{*}{$R_{\mathrm{s}}(\mathrm{ohm})$} & \multicolumn{2}{|c|}{$R_{\mathrm{p}}(\mathrm{ohm})$} \\
\hline & & & $15 \mu \mathrm{m}$ & $35 \mu \mathrm{m}$ \\
\hline bare & $1.0 \times 10^{-3}$ & 3 & $433^{*}$ & $433^{*}$ \\
\hline MA-AF & $7.1 \times 10^{-8}$ & 3 & 109460 & 717296 \\
\hline BPDA-AF & $2.6 \times 10^{-6}$ & 2 & 16727 & 117662 \\
\hline DDSA-AF & $3.2 \times 10^{-6}$ & 7 & 107340 & 1416359 \\
\hline $\mathrm{CB}_{6} \mathrm{~F}$ & $6.0 \times 10^{-7}$ & 1 & 40569 & 126519 \\
\hline BenzCB $_{6} \mathrm{~F}$ & $0.2 \times 10^{-6}$ & 10 & 93191 & 150047 \\
\hline $\mathrm{AsCB}_{6} \mathrm{~F}$ & $5.4 \times 10^{-6}$ & 3 & 10620 & 2618637 \\
\hline $\mathrm{CB}_{\mathrm{ZA}}-\mathrm{F}$ & $0.6 \times 10^{-3}$ & 3 & 27127 & 212068 \\
\hline $\mathrm{CC}_{\mathrm{A}} \mathrm{F}$ & $6.4 \times 10^{-7}$ & 1 & 110209 & 218858 \\
\hline $\mathrm{AsCB}_{\mathrm{As}} \mathrm{F}$ & $2.5 \times 10^{-6}$ & 14 & 24609 & 569829 \\
\hline
\end{tabular}

* For bare electrode thickness is zero.

TABLE 2: Impedance values for bare and coated copper.

\begin{tabular}{|c|c|c|c|c|}
\hline \multirow{2}{*}{ Electrode } & \multirow{2}{*}{$C_{\mathrm{dl}} / \mathrm{A}\left(\mathrm{F} / \mathrm{cm}^{2}\right)$} & \multirow{2}{*}{$R_{\mathrm{s}}(\mathrm{ohm})$} & \multicolumn{2}{|c|}{$R_{\mathrm{p}}(\mathrm{ohm})$} \\
\hline & & & $15 \mu \mathrm{m}$ & $35 \mu \mathrm{m}$ \\
\hline bare & $2.7 \times 10^{-6}$ & 2 & $8316^{*}$ & $8316^{*}$ \\
\hline MA-AF & $1.1 \times 10^{-6}$ & 7 & 10540 & 19600 \\
\hline BPDA-AF & $8.9 \times 10^{-7}$ & 5 & 18330 & 30369 \\
\hline DDSA-AF & $2.6 \times 10^{-6}$ & 11 & 21483 & 58327 \\
\hline $\mathrm{CB}_{6} \mathrm{~F}$ & $1.6 \times 10^{-6}$ & 2 & 9543 & 39672 \\
\hline BenzCB $_{6} \mathrm{~F}$ & $3.5 \times 10^{-6}$ & 53 & 34388 & 662790 \\
\hline $\mathrm{AsCB}_{6} \mathrm{~F}$ & $2.8 \times 10^{-6}$ & 24 & 32760 & 58175 \\
\hline $\mathrm{CB}_{\mathrm{ZA}}-\mathrm{F}$ & $7.7 \times 10^{-6}$ & 44 & 29337 & 2673309 \\
\hline $\mathrm{CC}_{\mathrm{A}} \mathrm{F}$ & $5.4 \times 10^{-6}$ & 7 & 31608 & 55077 \\
\hline $\mathrm{AsCB}_{\mathrm{As}} \mathrm{F}$ & $6.4 \times 10^{-6}$ & 11 & 10713 & 32640 \\
\hline
\end{tabular}

*For bare electrode thickness is zero.

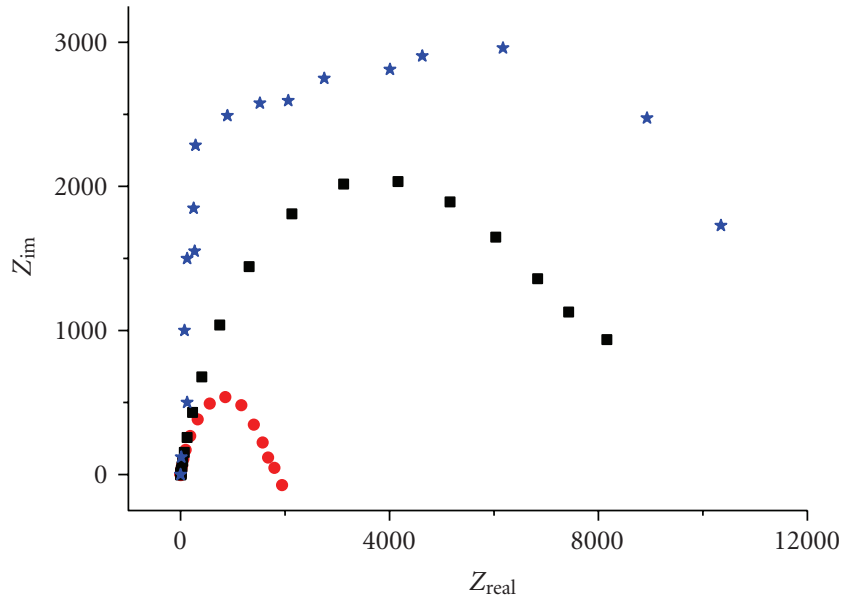

- $\mathrm{Cu}$

- DDSA-AF

$\star$ Paint

FIGURE 5: Nyquist diagrams for bare, resin, and paint coated copper.

as even paints contain some additives that increase their resistance and performance (Figure 5).

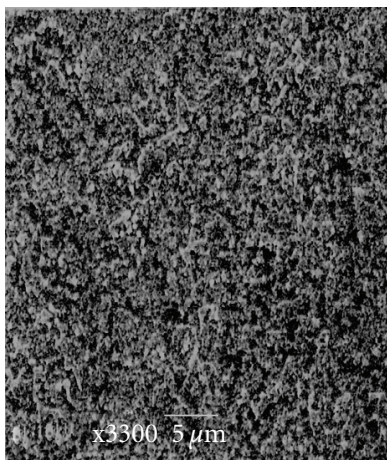

(a)

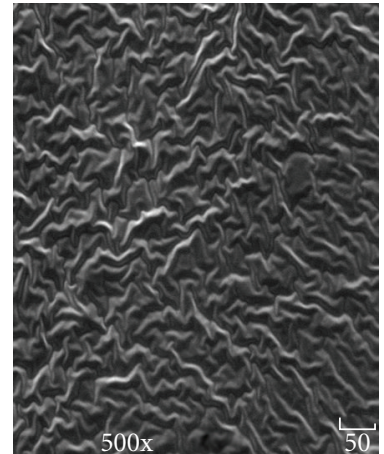

(b)
FIGURE 6: SEM pictures for SS (a) uncoated (b) DDSA coated.

3.1. Scanning Electron Microscope. Figure 6 show surface SEM images of the bare (a) and DDSA resin coated (b) SS electrodes, respectively. Coatings have continuous spaghettilike structure. The morphology of the coating appeared to be independent of the underlying metal and the films are homogeneous and uniform. 


\section{Conclusion}

Nine different ketonic resins have been successfully coated onto both stainless steel and copper. We can clasified resin into three group: first, MA-AF, BPDA-AF, DDSA-AF, second: CB6F, BenzCB6F, AsCB6F, and third: CBZA-F, CCAF, AsCBAsF. Each group has a main skeleton with different functional groups. When the $\mathrm{Rp}$ values of the first group compared they are increased in the order of DDSA-AF > $\mathrm{MA}-\mathrm{AF}>\mathrm{BPDA}-\mathrm{AF}$ for SS electrode and DDDA-AF > BPDA-AF > MA-AF for Cu electrode. Although for thinner films $(15 \mu \mathrm{m})$ the $\mathrm{Rp}$ values of DDSA-AF and MA-AFcoated SS are very close, as the thickness increase DDSAAF coating became more effective. This result suggests that as the number of - $\mathrm{COOH}$ group increases, and long alkyl chain introduced the structure, well-adherent and more resistive coating can be obtained for SS. On the other hand DDDA-AF seems the most effective coating for copper for both thicknesses, supporting the importance of functional groups (number of $-\mathrm{COOH}$ group and long alky chain) on the anticorrosive capacity of resin. For second group resin, although $-\mathrm{COOH}$ group that bound to aliphatic chain (AsCB6F) are effective for SS, presence of phenyl ring seems (BenzCB6F) to inscrese the effectivenes of -COOH group for copper. For third group, AsCBAsF resin as thicker coating seems the most effectives one for SS and CBZA-F resin coating is effective for copper.

All resins seem to be effective and stable in the protection of SS and copper by acting a physical barrier. The ability to provide corrosion protection appeared to be substrate specific that comes from the differences in the compactness and porosity of the films. In conclusion these resins will be used as a surface coating material in acidic medium that had not been done before.

\section{References}

[1] S. P. Sitaram, J. O. Stoffer, and T. J. O'Keefe, “Application of conducting polymers in corrosion protection," Journal of Coatings Technology, vol. 69, no. 866, pp. 65-69, 1997.

[2] V. A. Goldade, L. S. Pinchuk, A. V. Makarevich, and V. N. Kestelman, Plastics for Corrosion Inhibition, Springer-Verlag Berlin Heidelberg, 2005.

[3] F. Mansfeld, "Use of electrochemical impedance spectroscopy for the study of corrosion protection by polymer coatings," Journal of Applied Electrochemistry, vol. 25, no. 3, pp. 187-202, 1995.

[4] T. A. Misev and R. van Der Linde, "Powder coatings technology: new developments at the turn of the century," Progress in Organic Coatings, vol. 34, no. 1-4, pp. 160-168, 1998.

[5] E. Lugscheider, S. Bärwulf, C. Barimani, M. Riester, and H. Hilgers, "Magnetron-sputtered hard material coatings on thermoplastic polymers for clean room applications," Surface and Coatings Technology, vol. 108-109, pp. 398-402, 1998.

[6] T. Schauer, A. Joos, L. Dulog, and C. D. Eisenbach, "Protection of iron against corrosion with polyaniline primers," Progress in Organic Coatings, vol. 33, no. 1, pp. 20-27, 1998.

[7] U. Rammelt and G. Reinhard, "Application of electrochemical impedance spectroscopy (EIS) for characterizing the corrosion-protective performance of organic coatings on metals," Progress in Organic Coatings, vol. 21, no. 2-3, pp. 205226, 1992.

[8] T. Monetta, F. Bellucci, L. Nicodemo, and L. Nicolais, "Protective properties of epoxy-based organic coatings on mild steel," Progress in Organic Coatings, vol. 21, no. 4, pp. 353-369, 1993.

[9] P. L. Bonora, F. Deflorian, and L. Fedrizzi, "Electrochemical impedance spectroscopy as a tool for investigating underpaint corrosion," Electrochimica Acta, vol. 41, no. 7-8, pp. 10731082, 1996.

[10] J. E. O. Mayne, "The mechanism of the inhibition of the corrosion of iron and steel by means of paint," Official Digest, vol. 24, pp. 127-136, 1952.

[11] J. J. Oravitz, "Cathodic epoxy electrocoat for automotive radiators," Products Finishing, p. 220, 1997.

[12] F. M. Geenen, J. H. W. De Wit, and E. P. M. Van Westing, "An impedance spectroscopy study of the degradation mechanism for a model epoxy coating on mild steel," Progress in Organic Coatings, vol. 18, p. 299, 1990.

[13] F. Deflorian, L. Fedrizzi, and P. L. Bonora, "Determination of the reactive area of organic coated metals using the breakpoint method," Corrosion, vol. 50, no. 2, pp. 113-119, 1994.

[14] P. -H. Sung and C. -Y. Lin, "Polysiloxane modified epoxy polymer networks - I. Graft interpenetrating polymeric networks," European Polymer Journal, vol. 33, no. 6, pp. 903-906, 1997.

[15] H. Deligöz, T. Yalcinyuva, and S. Özgümüs, "A novel type of Sicontaining poly(urethane-imide)s: synthesis, characterization and electrical properties," European Polymer Journal, vol. 41, no. 4, pp. 771-781, 2005.

[16] P. R. Dvornic, H. J. Perpall, P. C. Uden, and R. W. Lenz, "Exactly alternating silarylene-siloxane polymers. VII. Thermal stability and degradation behavior of p-silphenylenesiloxane polymers with methyl, vinyl, hydrido, and/or fluoroalkyl side groups," Journal of Polymer Science A, vol. 27, no. 10, pp. 3503-3514, 1989.

[17] S. Bhuniya and B. Adhikari, "Toughening of epoxy resins by hydroxy-terminated, silicon-modified polyurethane oligomers," Journal of Applied Polymer Science, vol. 90, no. 6, pp. 1497-1506, 2003.

[18] A. Ashok Kumar, M. Alagar, and R. M. V. G. K. Rao, "Preparation and characterization of siliconized epoxy/ bismaleimide (N,N'-bismaleimido-4,4'-diphenyl methane) intercrosslinked matrices for engineering applications," Journal of Applied Polymer Science, vol. 81, no. 1, pp. 38-46, 2001.

[19] E. Sharmin, L. Imo, S. M. Ashraf, and S. Ahmad, "Acrylicmelamine modified DGEBA-epoxy coatings and their anticorrosive behavior," Progress in Organic Coatings, vol. 50, no. 1, pp. 47-54, 2004.

[20] G. Menges and W. Schneider, "Protective effect and complex resistance of protective linings made of chemical resistant polymers-1," Kunststofftechnik, vol. 12, no. 10, pp. 265-270, 1973.

[21] B. N. Grgur, M. M. Gvozdenović, V. B. Mišković-Stanković, and Z. Kačarević-Popović, "Corrosion behavior and thermal stability of electrodeposited PANI/epoxy coating system on mild steel in sodium chloride solution," Progress in Organic Coatings, vol. 56, no. 2-3, pp. 214-219, 2006.

[22] V. Karpagam, S. Sathiyanarayanan, and G. Venkatachari, "Studies on corrosion protection of Al2024 T6 alloy by electropolymerized polyaniline coating," Current Applied Physics, vol. 8, no. 1, pp. 93-98, 2008.

[23] M. G. Hosseini, M. Sabouri, and T. Shahrabi, "Corrosion protection of mild steel by polypyrrole phosphate composite coating," Progress in Organic Coatings, vol. 60, no. 3, pp. 178$185,2007$. 
[24] J. Flis and M. Kanoza, "Electrochemical and surface analytical study of vinyl-triethoxy silane films on iron after exposure to air," Electrochimica Acta, vol. 51, no. 11, pp. 2338-2345, 2006.

[25] S. Y. Zhang, W. F. Zhou, X. W. Luo, and S. J. Li, "Evaluation of thin defect-free epoxy coatings using electrochemical impedance spectroscopy," Journal of Applied Electrochemistry, vol. 28, no. 11, pp. 1277-1281, 1998.

[26] G. Lendvay-Gyorik, T. Pajkossy, and B. Lengyel, "Corrosionprotection properties of water-borne paint coatings as studied by electrochemical impedance spectroscopy and gravimetry," Progress in Organic Coatings, vol. 56, no. 4, pp. 304-310, 2006.

[27] I. Sekine, M. Yuasa, N. Hirose, and T. Tanaki, "Degradation evaluation of corrosion protective coatings by electrochemical, physicochemical and physical measurements," Progress in Organic Coatings, vol. 45, no. 1, pp. 1-13, 2002.

[28] M. R. Bagherzadeh and F. Mahdavi, "Preparation of epoxyclay nanocomposite and investigation on its anti-corrosive behavior in epoxy coating," Progress in Organic Coatings, vol. 60, no. 2, pp. 117-120, 2007.

[29] J. M. Yeh, H. Y. Huang, C. L. Chen, W. F. Su, and Y. H. Yu, "Siloxane-modified epoxy resin-clay nanocomposite coatings with advanced anticorrosive properties prepared by a solution dispersion approach," Surface and Coatings Technology, vol. 200, no. 8, pp. 2753-2763, 2006.

[30] G. M. Spinks, A. J. Dominis, G. G. Wallace, and D. E. Tallman, "Electroactive conducting polymers for corrosion control: part 2. Ferrous metals," Journal of Solid State Electrochemistry, vol. 6, no. 2, pp. 85-100, 2002.

[31] N. Kizilcan and A. Akar, "Modification of acetophenoneformaldehyde and cyclohexanone-formaldehyde resins," Journal of Applied Polymer Science, vol. 60, no. 3, pp. 465-476, 1996.

[32] N. Kızılcan, O. Galioğlu, and A. Akar, "Modified cyclohexanone-formaldehyde and acetophenone-formaldehyde resins," Journal of Applied Polymer Science, vol. 50, no. 4, pp. 577-584, 1993.

[33] N. Kizilcan and A. Akar, "In situ modified reactive cyclohexanone-formaldehyde resins," Angewandte Makromolekulare Chemie, vol. 266, pp. 1-6, 1999. 


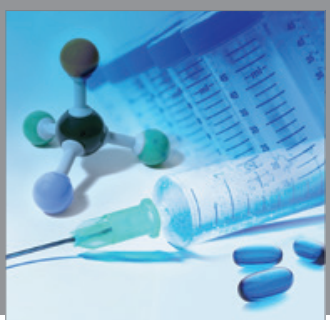

International Journal of

Medicinal Chemistry

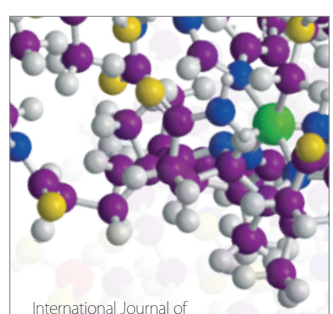

Carbohydrate Chemistry

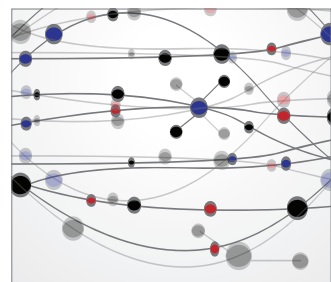

The Scientific World Journal
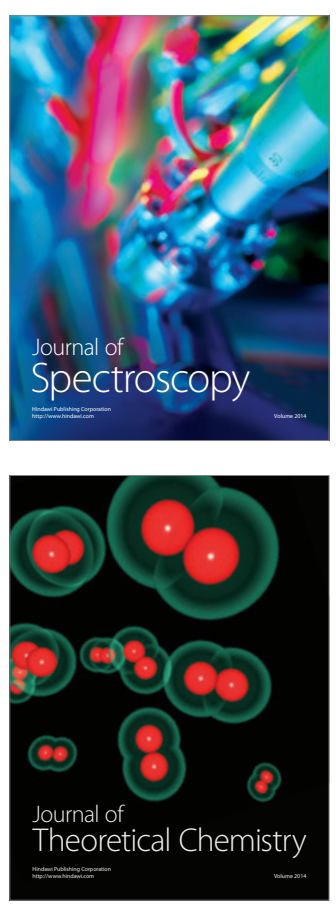
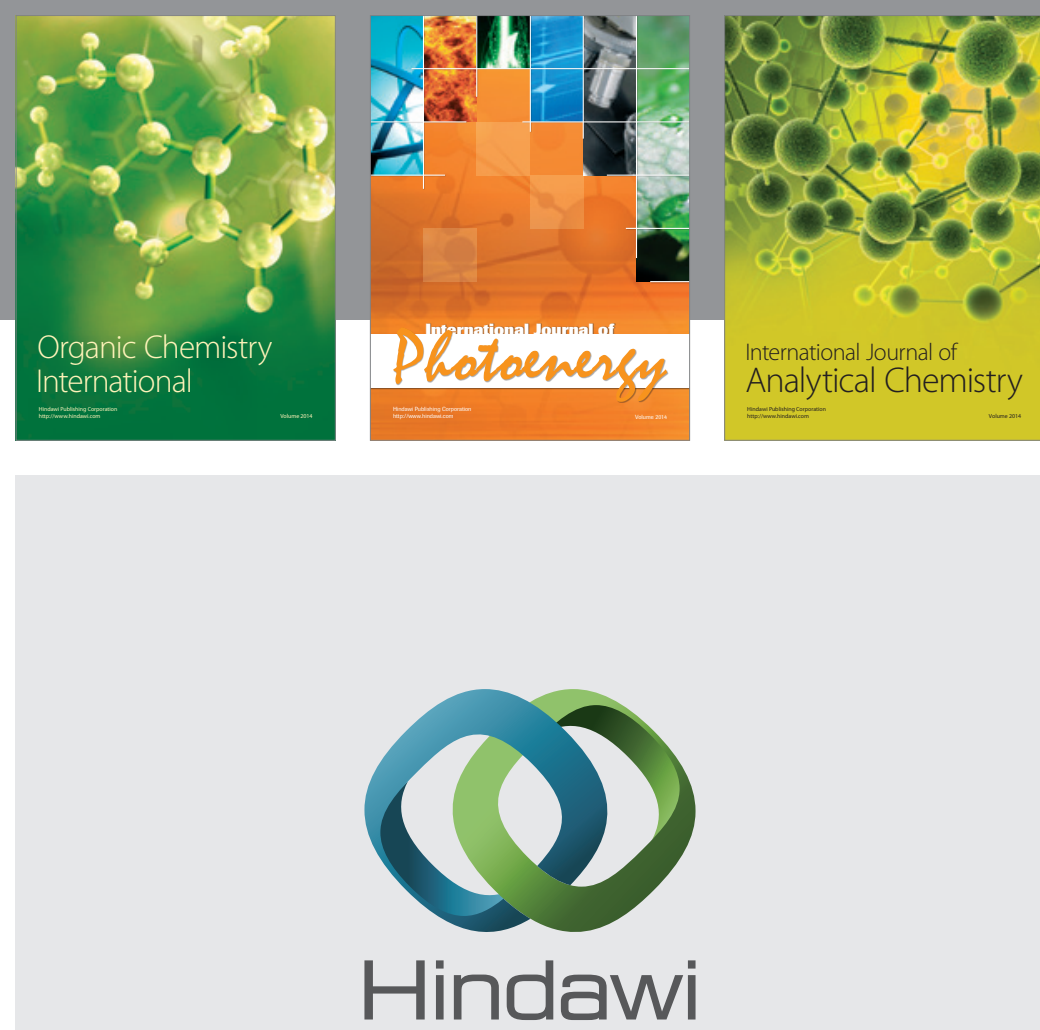

Submit your manuscripts at

http://www.hindawi.com
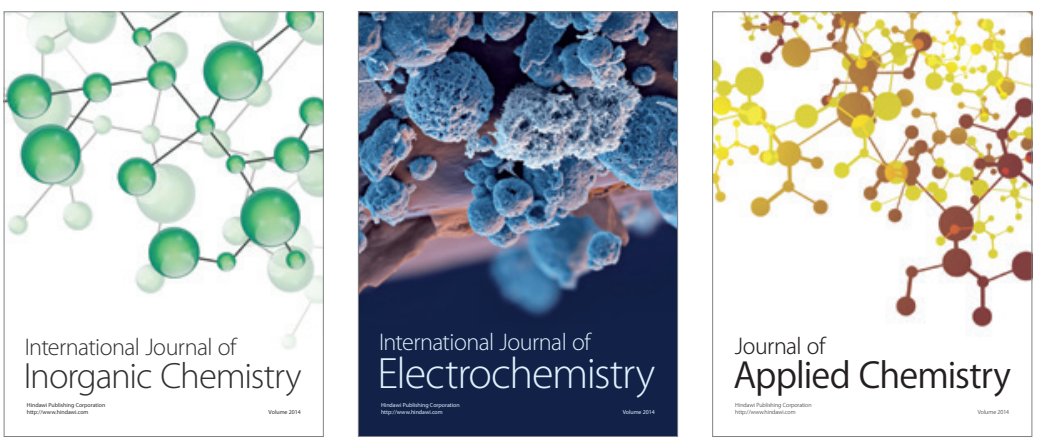

Journal of

Applied Chemistry
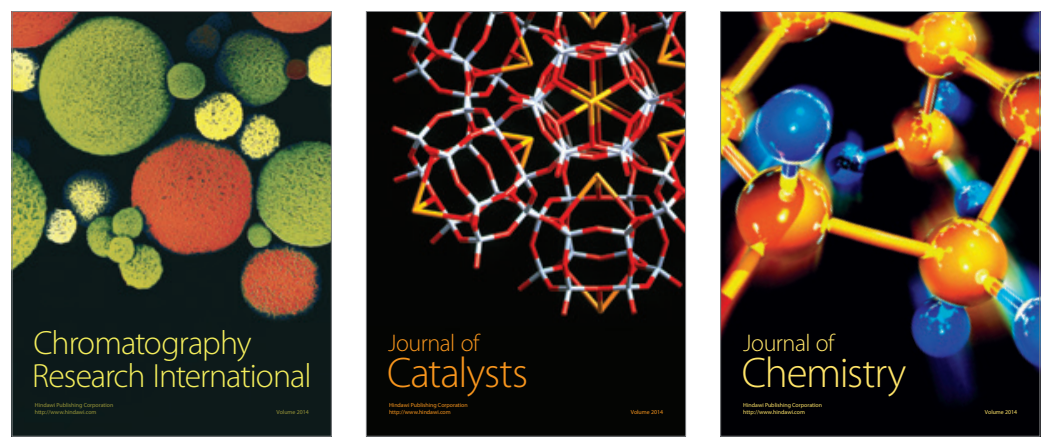
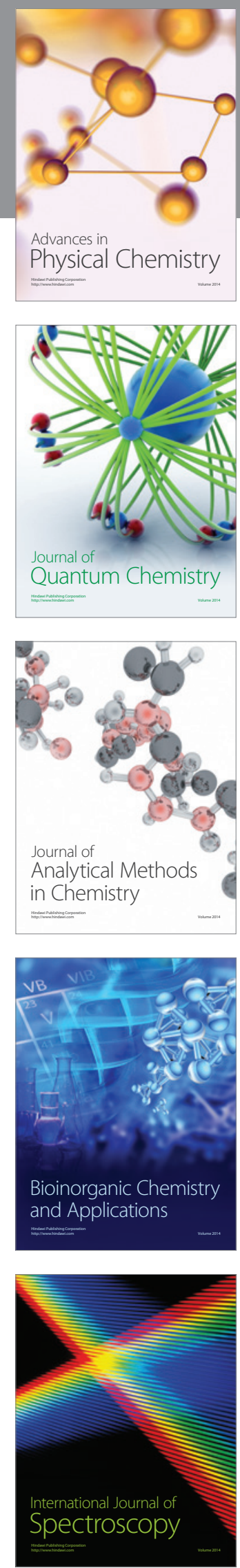